\title{
Decline in Relative Strength with Increasing the Body Weight: a Study on Heavy Weight Categories Powerlifters
}

Haridas K

Asst. Director of Physical education, Mangalore University, India

Corresponding Author: Haridas K, E-mail: hkuloor@gmail.com

\section{ARTICLE INFORMATION}

Received: August 21, 2020

Accepted: September 25, 2020

Volume: 2

Issue: 5

\section{KEYWORDS}

Relative strength, heavy weight, powerlifter, body size

\section{ABSTRACT}

Relative strength is the amount of strength to the body size. It is the strength to body weight ration. When body size is more, we generally understand that the strength is more with the player. In strength sports like weight lifting, powerlifting the strength of the individual is measured. In weight lifting, the total of snatch, clean and jerk are the factors to decide the winner; however, in powerlifting the total of squat, bench press and deadlift are considered. In this study, 54 senior class powerlifter and 54 junior class powerlifters are treated as subjects. All the subjects from heavy weight categories such as $105 \mathrm{~kg}, 120 \mathrm{~kg}$ and above $120 \mathrm{~kg}$ categories are highlighted. The results of the study revealed that the relative strength is decreasing with the increased body weight.

\section{Introduction}

Powerlifting is one of the major strength sports in India. Every year the competitions for different categories are conducted. The age categories are sub junior, junior, senior Master I, Master II, Master III and Master IV for men and women separately. There are weight categories for men (08) and for women (07).

There are three events in powerlifting. They are squat, bench press and deadlift. In the competition first it measures lower body strength (squat) then upper body strength (bench press) and at the end deadlift event. In all the three events there will be three attempts. The highest successful score of squat, bench press and deadlift are considered for total weight for awarding the winners.

Absolute strength is the maximum amount of force exerted, regardless of muscle or body size. In powerlifting the actual performance of the competitor in squat, bench press and deadlift are may be considered as absolute strength to the player's bodyweight.

Relative strength is the amount of strength to body size, or how strong someone is compared to their size. The relative strength is measured by dividing the actual performance (in weight) by the player's actual body weight. It is the strength to body weight ratio.

In the competition the competitor may reduce his/her bodyweight according to the strategies to get the medals. One may reduce or other may increase the weight when he/she goes to the weigh-in prior to the competition. The reduction or increasing the body mass may affect the player's performance as well as relative strength. The reducing or increasing body weight may not impact more on heavy weight classes. Because in heavy class category the lifters are having more fat which can be easily burnt to reduce body weight without any harmful attempts.

The study aims to highlight the relative strength variation during the increased body weight of individuals.

\section{Methodology}

Data is collected from the results of national level senior and junior level competitions organized by powerlifting in India. The three years results were taken into consideration. In male section heavy weight class $(105 \mathrm{~kg}, 120 \mathrm{~kg}$, and $+120 \mathrm{~kg})$ powerlifting

\footnotetext{
K C AL-KINDI CENTER R D FOR RESEARCH AND R D DEVELOPMENT
} Your gateway to world-class research
Published by Al-Kindi Center for Research and Development. Copyright (c) the author(s). This is an open access article under CC BY license (https://creativecommons.org/licenses/by/4.0/) 
results best six performance of each class in junior and senior category was selected for this study. 54 from senior and 54 from junior category results were taken as subjects for this study.

\section{Statistical analysis}

All the data was analyzed by using proper statistical techniques. Relative strength was calculated for all powerlifters at each competition by dividing their highest performance by their bodyweight. The relative strength score was calculated for each lift such as squat, bench-press and deadlift. The athletes weigh in occurs one to two hours before the commencement of competition. The nutritional and body weight management strategies may cause to slight variation on relative strength performance.

Table I shows the mean value of absolute weight of lifters performed in the competition. It is the maximum lift performed in heavy weight categories such as $105 \mathrm{~kg}, 120 \mathrm{~kg}$ and $+120 \mathrm{~kg}$ category in male junior and senior section at the national level competitions. The absolute strength of squat, bench press and deadlift were taken in consideration separately.

Table I. Absolute weight lifted in junior and senior category for the squat, bench-press and deadlift

\begin{tabular}{|l|l|l|l|l|l|l|l|}
\hline & & \multicolumn{3}{|l}{$105 \mathrm{~kg}$} & $120 \mathrm{~kg}$ & \multicolumn{1}{l|}{$+120 \mathrm{~kg}$} \\
\hline Category & & Mean & SD & Mean & SD & Mean & SD \\
\hline \multirow{4}{*}{ Junior } & Squat & 267.39 & 35.39 & 284.83 & 46.21 & 305.44 & 49.75 \\
\cline { 2 - 8 } & Bench press & 166.61 & 35.38 & 172.89 & 29.51 & 187.47 & 30.42 \\
\cline { 2 - 8 } & Dead lift & 251.56 & 27.51 & 250.08 & 31.31 & 263.03 & 32.69 \\
\hline \multirow{3}{*}{ Seniors } & Squat & 347.83 & 28.60 & 356.53 & 21.64 & 356.25 & 44.32 \\
\cline { 2 - 8 } & Bench press & 212.22 & 25.52 & 221.11 & 18.77 & 222.64 & 30.66 \\
\cline { 2 - 8 } & Dead lift & 291.11 & 26.45 & 296.53 & 24.36 & 287.5 & 27.84 \\
\hline
\end{tabular}

\section{fig. 1a Relative strength of senior heavy weight powerlifters for squat, bench press and deadlift}

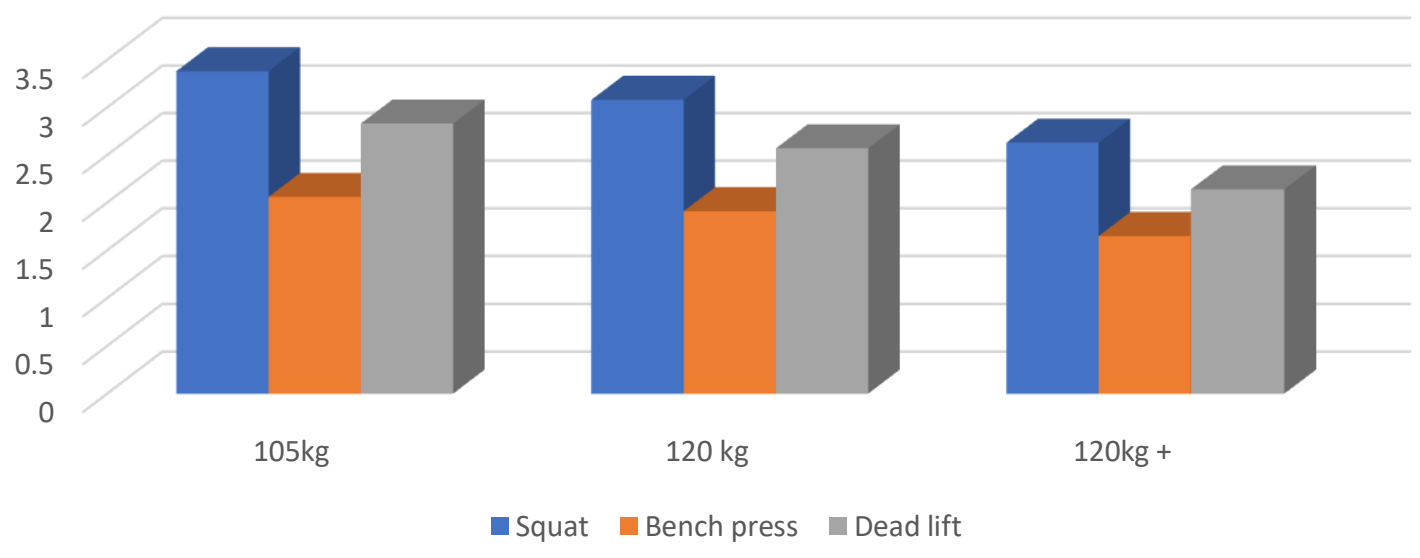

Figure 1a shows the relative strength for the squat, bench-press and deadlift in senior male category in heavy weight classes. It is observed that the $105 \mathrm{~kg}$ class had the highest relative strength score than $120 \mathrm{~kg}$ and $+120 \mathrm{~kg}$ class. The squat relative strength score were decreasing from $105 \mathrm{~kg}$ weight class $(3.380 .26)$ to $120 \mathrm{~kg}$ class $(3.080 .18)$ and $+120 \mathrm{~kg}$ weight class $(2.63$ $0.24)$. The bench press relative strength score also in decreasing form $105 \mathrm{~kg}$ weight class (2.06 0.24$)$ to $120 \mathrm{~kg}$ class (1.91 0.17$)$ and $+120 \mathrm{~kg}$ weight class $(1.650 .20)$. The dead lift relative strength score also found decreasing form $105 \mathrm{~kg}$ weight class (2.83 0.27 ) to $120 \mathrm{~kg}$ class $(2.570 .27)$ and $+120 \mathrm{~kg}$ weight class $(2.140 .24)$. 


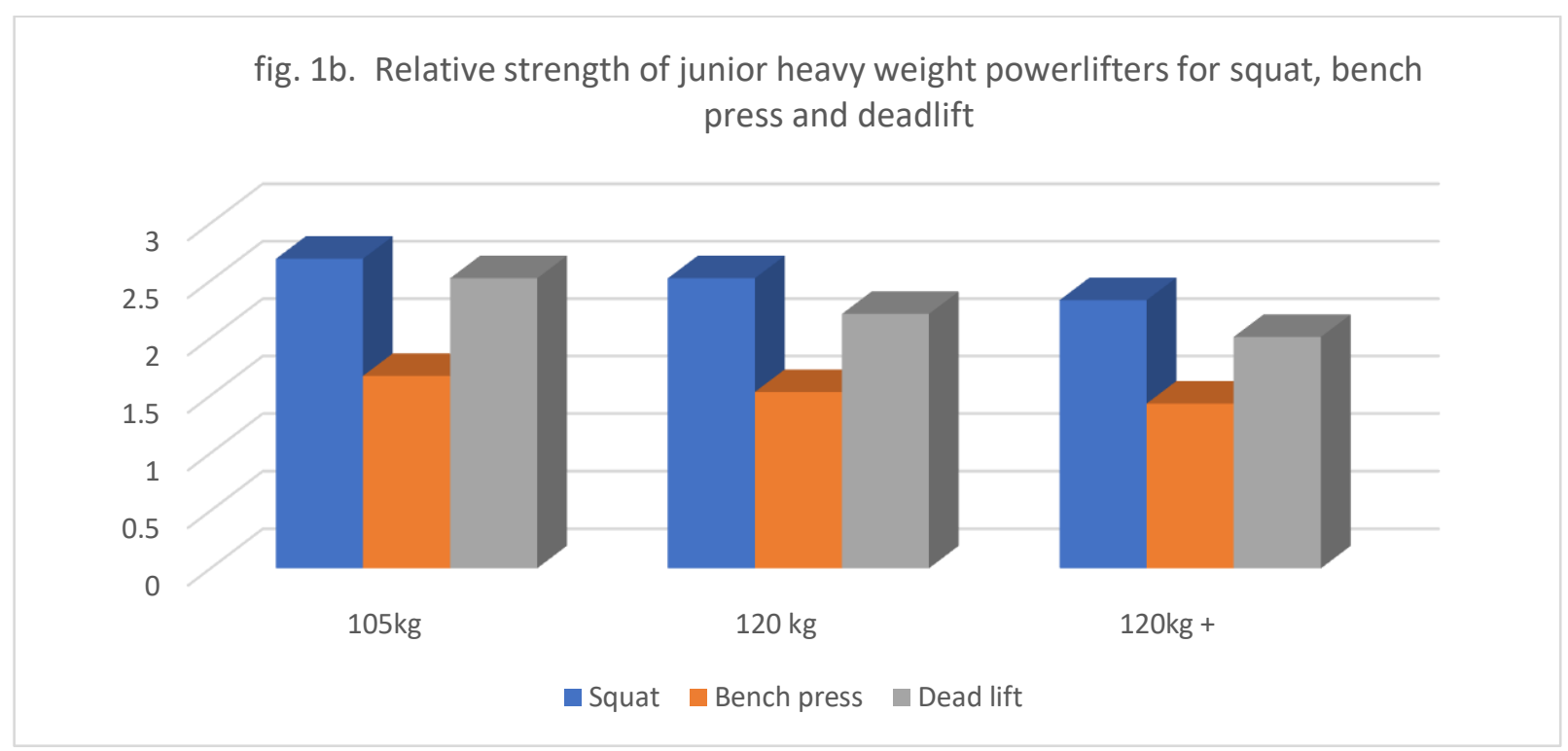

Figure $1 \mathrm{~b}$ shows the relative strength for the squat, bench-press and deadlift in junior male category in heavy weight classes. It is observed that the $105 \mathrm{~kg}$ class had the highest relative strength score than $120 \mathrm{~kg}$ and $+120 \mathrm{~kg}$ class. The squat relative strength score were decreasing from $105 \mathrm{~kg}$ weight class $(2.690 .39)$ to $120 \mathrm{~kg}$ class $(2.520 .39)$ and $+120 \mathrm{~kg}$ weight class $(2.33$ $0.42)$. The bench press relative strength score also in decreasing form $105 \mathrm{~kg}$ weight class $(1.670 .36)$ to $120 \mathrm{~kg}$ class $(1.530 .27)$ and $+120 \mathrm{~kg}$ weight class $(1.430 .27)$. The dead lift relative strength score also found decreasing form $105 \mathrm{~kg}$ weight class (2.52 0.29 ) to $120 \mathrm{~kg}$ class $(2.210 .30)$ and $+120 \mathrm{~kg}$ weight class $(2.010 .33)$.

\section{Discussion}

The purpose of this study is to find out the strength to body weight ratio variations in heavy weight class powerlifters. It is investigated on selected three body weight classes in junior and senior section male powerlifting. The result shows that the strength to body weight ratio for squat is greater than strength to body weight ratio for Bench press and deadlift in junior and seniors respectively.

It was observed that the relative strength ratio is decreasing when the body mass increasing in junior and senior section heavy weight categories. These finding was similar to those investigation done by Christopher Latella (2018) on powerlifters.

The both upper body relative strength and lower body relative strength were decreasing in both junior and senior male heavy body weight class powerlifting categories. Christopher Latella (2018) reported similar findings on their investigation.

The results shows that relative strength decline ratio more in first $(105 \mathrm{Kg})$ to second $(120 \mathrm{~kg})$ weight class than second to third (+120 kg) weight class. It is understood that the decline ratio is more when the body mass is increasing. The lower body relative strength (Squat) decline ratio is higher than upper body relative strength (Bench press) declining. The decline ratio in senior heavy weight class is higher than junior heavy weight class powerlifters.

\section{Conclusion}

The objective of the study was to analyze the relative strength of powerlifters in different bodyweight categories. For these three years national level senior and junior level powerlifting championships, the results were taken into consideration. The best six performance of male section in heavy weight class $(105 \mathrm{~kg}, 120 \mathrm{~kg}$, and $+120 \mathrm{~kg})$ category results was analyzed. The results of this study shows that there was a difference in relative strength between juniors and senior of heavy weight class male powerlifters. The relative strength is in decline with increasing body mass. The less body mass shows higher relative strength and heavy weight class male powerlifters are comparatively low in relative strength. This result may help the powerlifters and the coaches to adopt systematic training according to the relative strength. 


\section{References}

[1] Alam, S. (2017). Assessment of relative strength between south Asian and all India inter university male weightlifters.

[2] Alam, S. (2017). A comparative study of relative strength between men and women elite junior national weightlifters.

[3] Bishop, P. A., Williams, T. D., Heldman, A. N., \& Vanderburgh, P. M. (2018). System for evaluating powerlifting and other multievent performances. The Journal of Strength \& Conditioning Research, 32(1), 201-204.

[4] Brechue, W. F., \& Abe, T. (2002). The role of FFM accumulation and skeletal muscle architecture in powerlifting performance. European journal of applied physiology, 86(4), 327-336.

Ebada, K. H. (2011). Relative strength, body mass and height as predictors of olympic weightlifting players performance. Selçuk University Journal of Physıcal Education and Sport Science, 13(2), 166-171.

[6] Ferland, P. M., \& Comtois, A. S. (2019). Classic powerlifting performance: a systematic review. The Journal of Strength \& Conditioning Research, 33, S194-S201.

[7] Mayhew, J. L., McCormick, T. P., Piper, F. C., Kurth, A. L., \& Arnold, M. D. (1993). Relationships of body dimensions to strength performance in novice adolescent male powerlifters. Pediatric Exercise Science, 5(4), 347-356.

[8] Hales, M. E., Johnson, B. F., \& Johnson, J. T. (2009). Kinematic analysis of the powerlifting style squat and the conventional deadlift during competition: is there a cross-over effect between lifts?. The Journal of Strength \& Conditioning Research, 23(9), $2574-2580$.

[9] Haridas. (2020). Influence of special suites on enhancing the performance in power lifting, IJAEM, 2(2), 152-155.

[10] Latella, C., Van den Hoek, D., \& Teo, W. P. (2018). Factors affecting powerlifting performance: an analysis of age-and weight-based determinants of relative strength. International Journal of Performance Analysis in Sport, 18(4), 532-544. 